\title{
A construção de material pedagógico para o ensino do jogo e o processo educativo na Educação Física crítico-superadora
}

\section{RESUMO}

Este estudo originou-se nos Estágios Curriculares Supervisionados (ECS) do Curso de Educação Física - UFSM. Período em que houve a necessidade de construir material pedagógico para o trato com o conteúdo jogo. Objetivamos analisar a importância da participação do educando na construção de material pedagógico para seu processo educativo. Metodologicamente pauta-se por um relato de experiência. Utilizamos registros sistemáticos das aulas com uma turma de $4^{\circ}$ ano da rede Estadual de Ensino Fundamental de SM - RS. Elaboramos nossa proposta de trabalho e lapidamos nossos resultados com base na Pedagogia Histórico - Crítica e na Concepção Crítico - Superadora. Como contribuições destacam-se a capacidade de análise da realidade, apropriação de novos materiais pedagógicos e ampliação da Cultura Corporal. Concluímos que as contribuições ultrapassam o contato com novas práticas corporais e expressam a capacidade de transformar coletivamente o cenário escolar.

PALAVRAS-CHAVE: Educação física escolar; Material pedagógico; Jogo; Processo educativo
Gislei José Scapin

Especialista em Educação Física Escolar Universidade Federal de Santa Maria - UFSM, Centro de Educação Física e Desportos, Santa Maria,

Rio Grande do Sul, Brasil gjscapin@gmail.com https://orcid.org/0000-0002-6996-2158

Maria Cecília da Silva Camargo Doutora em Ciências do Movimento Humano Universidade Federal de Santa Maria - UFSM, Departamento de Desportos Individuais, Santa Maria,

Rio Grande do Sul, Brasil

mceciliacg6@hotmail.com https://orcid.org/0000-0002-5542-4009

Maristela da Silva Souza

Doutora em Ciência do Movimento Humano Universidade Federal de Santa Maria - UFSM, Departamento de Desportos Individuais, Santa Maria,

Rio Grande do Sul, Brasil maristeladasilvasouza@yahoo.com.br ${ }^{\circ}$ https://orcid.org/0000-0002-9624-3060

Leandra Costa da Costa

Doutora em Educação

Universidade Federal de Santa Maria - UFSM, Departamento de Desportos Individuais, Santa Maria,

Rio Grande do Sul, Brasil lcostadacosta@hotmail.com https://orcid.org/0000-0002-2134-9354

Carine Marques Charão

Mestre em Educação Física Secretaria de Educação do Rio Grande do Sul, Santa Maria, Rio Grande do Sul, Brasil carinemarxcharao@gmail.com https://orcid.org/0000-0002-0576-139X 
The construction of pedagogical material for the game teaching and the educative process in Physical Education critical-overcomer

\begin{abstract}
This study was originated in Supervised Curricular Internships (SCI) of Physical Education Course - UFSM. Period which there was the need of construct pedagogical material for tract with the content game. We objected the importance of the student participation in construction of pedagogic material for their educative process. Methodologically it's scheduled by an experience report. We use systematic class records with a student class of $4^{\text {th }}$ year of State Web Teaching of Santa Maria RS. We elaborate our work proposal and we lapped our results with base in the Pedagogy Historical - Critique and in Critique Conception - Overcomer. As contributions we stand out the capacity to analyze reality, appropriation o new pedagogical materials and enlargement of body culture. We conclude that the contributions exceed the contact with new bodily practices and express the capacity of transform collectively the school scenery.
\end{abstract}

KEYWORDS: School physical education; Pedagogical materials; Game; Educative process

\title{
La construcción de material pedagógico para la enseñanza del juego y el proceso educativo en la Educación Física crítica-superadora
}

\section{RESUMEN}

Ese estudio se originó en las Pasantías Curriculares Supervisadas (PCS) de la carrera de Educación Física - UFSM. Período en el que hubo la necesidad de construir material pedagógico para el trato con el contenido juego. Objetivamos analizar la importancia de la participación del educando en la construcción del material pedagógico para su proceso educativo. Metodológicamente es guiada por un relato de experiencia. Utilizamos registros sistemáticos de las clases con un grupo de $4^{\circ}$ año de la rede Estadual de Enseñanza Fundamental de SM, RS. Elaboramos nuestra propuesta de trabajo y lapidamos nuestros resultados con base en la Pedagogía Histórico - Crítica y en la Concepción Crítico - Superadora. Como contribuciones se destacan la capacidad de análisis de realidad, apropiación de nuevos materiales pedagógicos y ampliación de la cultura corporal. Concluimos que las contribuciones ultrapasan el contacto con nuevas prácticas corporales y expresan la capacidad de transformar colectivamente el escenario escolar.

PALABRAS-CLAVE: Educacíon física escolar; Material pedagógico; Juego; Proceso educativo 


\section{INTRODUÇÃO}

Este estudo é oriundo das experiências vividas durante o processo de formação inicial de professores no curso de Educação Física - Licenciatura (CEFD/UFSM), especificamente no período dos Estágios Curriculares Supervisionados $(\mathrm{ECS})^{1}$, a partir da segunda metade do curso. Nesse período vivemos experiências fundamentais à formação docente que extrapolam os muros da universidade, momentos de conhecimento sobre a realidade profissional que nos espera após a etapa acadêmica/universitária.

No referido contexto, encontramos uma condição precária de materiais pedagógicos disponíveis para as aulas de Educação Física, uma realidade deparada nas escolas públicas, como destacam Betti (1999), Rodrigues; Darido (2011) e Teixeira; Soares; Ferreira (2018), revelando uma restrição muito grande em relação a estrutura física e material para aulas de Educação Física, influenciando até mesmo na seleção dos conteúdos a serem trabalhados.

Na perspectiva de Soares et al. (2012, p.64), a realidade material da escola é fundamental para apropriação dos conhecimentos da Educação Física, pois "supõe a adequação de instrumentos teóricos e práticos, sendo que algumas habilidades corporais exigem, ainda, materiais específicos”.

Deste modo, decidimos realizar a construção de materiais pedagógicos junto aos alunos. Com esse proveito, visamos a possibilidade de apropriação dos elementos da Cultura Corporal, tendo o material pedagógico como papel de facilitador do processo de ensino-aprendizagem, auxiliando o trabalho do professor como salienta Zabala (1998). Assim, possibilitamos o desenvolvimento do conteúdo jogo, apresentado na obra Metodologia do Ensino da Educação Física de Soares et al.(2012) e, ademais, atendendo ao plano de ensino proposto para/pela ${ }^{2}$ escola onde foi desenvolvida a prática.

A partir deste contexto elaboramos como objetivo analisar a importância da participação do educando na construção do material pedagógico para o seu processo de formação educativa, elencando as contribuições que emergiram deste processo participativo e a capacidade de transformação de sua realidade para benefício coletivo, a partir de um recorte das ações pedagógicas realizadas no período de ECS III $^{3}$.

${ }^{1}$ O ECS presente no Centro de Educação Física e Desportos - UFSM, como apresenta seu Regimento Interno aprovado em 1990, no capitulo VII e sessão II, é uma disciplina de culminância curricular que se desenvolve sob a forma de estágio aberto (Art. 113, p. 25), com os seguintes objetivos específicos: Conhecer a estrutura e o funcionamento do campo de experiências escolhido, visando a uma adequada integração profissional; Planejar as atividades a serem desenvolvidas como experiência para a futura profissão; Vivenciar as experiências escolhidas sobre a orientação de um profissional da área; Analisar as atividades desenvolvidas a fim de oferecer subsídios que contribuam para um replanejamento da própria atividade, bem como, de toda a estrutura curricular do curso (RICEFD, 1990).

${ }^{2} \mathrm{~A}$ escola nos apresentou um plano de ensino com a proposta de trabalho, mas, pautado neste plano e nas condições em que nos encontrávamos, elaboramos outra proposta de trabalho que estabeleceu todo o período de estágio da escola. 
Justificando nossa ação, podemos realizar alguns apontamentos sobre a realização deste estudo. Trazemos para discussão o processo de construção de material pedagógico para a formação educativa dos educandos, não direcionando apenas para o momento de transmissão do conteúdo e realização de atividades práticas, mas preocupando-nos com o educando enquanto sujeito em formação, destacando a importância de sua participação nas realizações coletivas/escolares, com a intenção de solucionar ou atenuar alguns problemas encontrados na escola, como a falta de materiais pedagógicos, buscando a capacidade de análise e entendimento de sua realidade, os problemas nela existentes e propiciar meios de criar mecanismos para a superação dos mesmos.

Nosso trabalho constituiu-se por um relato de experiência a partir do ECS III, realizado em uma escola pública da rede estadual no município de Santa Maria-RS. Afim de viabilização do trabalho desenvolvido, utilizamos os registros sistemáticos das aulas com intuito de rever as anotações, sistematizando as observações e intervenções, colaborando para organização dos conteúdos, planejamento e elaboração dos materiais. Nos registros sistemáticos averbamos todas as informações e observações dos fatos concretos, acontecimentos, reflexões e comentários sobre as aulas para que fossem usados e retomados, sendo um instrumento de interpretação e interrogação (BOGDAN e BIKLEN, 1994).

O ECS III foi realizado com uma turma do $4^{\circ}$ ano do Ensino Fundamental, de uma Escola da Rede Estadual de Ensino da cidade de Santa Maria- RS. A escola situa-se na região central da cidade e recebe alunos de regiões próximas e com diferentes condições socioeconômicas. Os espaços externos destinados às aulas de Educação Física dispunham de uma quadra poliesportiva sem cobertura destinada às aulas com Ensino Fundamental - Anos Finais e Ensino Médio, e um espaço aberto para uso do Ensino Fundamental - Anos Iniciais. O período de duração do ECS III foi entre os meses de abril e julho de 2016, as aulas eram realizadas duas vezes por semana.

Em síntese, nosso estudo se organiza em um relato de experiência realizado no período de Estagio Curricular apresentando o campo de atuação, a proposta de trabalho com a construção de materiais pedagógicos e a organização didática; logo após, apresentamos uma análise dessa experiência, trazendo para discussão a participação do educando no processo de construção de material pedagógico e as contribuições para sua formação educativa partindo ao encontro dos objetivos traçados para este trabalho.

\footnotetext{
${ }^{3}$ Os estágios estão organizados em três disciplinas de caráter obrigatório, sendo denominadas por Estágio Curricular Supervisionado I, II e III, os quais correspondem, respectivamente, as etapas da educação básica: Ensino Médio, Ensino Fundamental - Anos Finais e Ensino Fundamental - Anos Iniciais. Durante o período de sua realização, o acadêmico é acompanhado por dois professores/profissionais da área, sendo um Professor Orientador, responsável pela disciplina do curso de formação e por um Professor Supervisor, regente do componente curricular na escola, ambos são responsáveis pelo desenvolvimento e avaliação do estágio.
} 


\section{Estratégia para o trato pedagógico}

Iniciando o processo de exposição das estratégias planejadas e desenvolvidas para o trato com o conhecimento da Educação Física, sobretudo, os jogos, a partir da construção de material de pedagógico, é mister situarmos qual a natureza e especificidade deste material. Na perspectiva de Sacristán (1991), o material pedagógico é entendido como instrumentos, objetos e ferramentas que, ao serem manipulados, desempenham uma função na qualidade de recurso de ensino, possibilitando, portanto, a aprendizagem de determinado conhecimento. Para Aguiar; Roteli; Terra (2005), os materiais pedagógicos podem ser concebidos em dois momentos, a saber: o material que o professor utiliza para elaborar seu planejamento e aquele utilizado junto aos educandos no processo de ensino-aprendizagem. No corrente trabalho, estaremos fazendo referência ao segundo momento de conceber o material pedagógico.

No cenário escolar, nos deparamos com educandos que demonstravam anseios por conhecimentos e vivências de movimentos corporais, porém tinham suas experiências limitadas em virtude da falta de materiais pedagógicos e espaço físico sucateado. No que tange aos materiais disponibilizados para a etapa do Ensino Fundamental - Anos Iniciais tínhamos apenas à nossa disposição algumas bolas de basquetebol e uma corda.

Desta forma, tivemos por estratégia a construção de materiais pedagógicos utilizando-se de materiais alternativos e/ou recicláveis. Nossa ação pedagógica compactua com o posicionamento de Amaral (1988), pois também entendemos que os objetos que estariam sendo descartados ou não serviriam mais para o uso, podem ser transformados e receber o caráter educativo, tendo seu uso para proporcionar o acesso a outros conhecimentos. Do mesmo modo, concordamos com o argumento de Tahara; Darido; Bahiax (2017) ao explicarem que a elaboração de material pedagógico de forma colaborativa, a partir das experiências do professor, propicia a organização e reflexão sobre as possibilidades de ensino e aprendizagem do saber escolar.

Rocha (2005, p. 31), menciona a relevância do material pedagógico, em especial, para o trabalho com crianças quando evidencia a mediação por meio dos instrumentos, sendo a “interposição de apoios externos, concretos, que possibilitem ao indivíduo lidar com a realidade de uma forma indireta, ampliando, enormemente, suas possibilidades de ação sobre o mundo”, desta forma apropriando-se destes instrumentos para desenvolver-se enquanto ser humano, na posição de sujeito histórico ${ }^{4}$ cultural.

${ }^{4}$ Trabalhamos com a concepção de homem/sujeito histórico pautado em Saviani (2012) e Saviani (2013). 
Conforme explicação de Aguiar; Roteli; Terra (2005), no que se refere aos materiais pedagógicos específicos para Educação Física, há tendência de imediatamente situarmos e limitarmos nosso horizonte de compreensão aos materiais de uso convencional utilizados na prática de atividade física como, por exemplo, bolas, cordas, bastões, cones, entre outros. Entretanto, concordamos com os autores ao ponderarem a necessidade de ampliarmos nosso entendimento em relação ao manuseio e utilização dos referidos materiais, para que possamos juntos aos educandos, não apenas restringir o uso de recursos pedagógicos para aprimoramento das habilidades e das destrezas físicas, mas sim, contribuir para a aprendizagem e desenvolvimento intelectual e cultural dos mesmos.

Para o processo da construção de novos materiais pedagógicos, ocorrido na primeira semana de aula, após o contato inicial e observações das aulas do professor regente, solicitamos aos alunos que colaborassem e participassem trazendo materiais que pudessem ser reutilizados, de fácil acesso e que não apresentasse riscos ao manuseá-los. Com base em uma lista previamente elaborada e divulgada para os educandos, arrecadamos materiais ${ }^{5}$ e realizamos a organização e seleção dos mesmos para que finalmente pudessem ser transformados e receber um caráter pedagógico e lúdico. Ademais, confeccionamos: pinos, bolinhas de meia, tacos, bastões, piões, bilboquês (brinquedos).

Nesse ínterim, é importante destacar a intensa participação dos educandos no processo de confecção dos materiais acima mencionados evidenciando o contentamento ao participarem da atividade proposta. Corroborando com Benjamim (1984, p. 69) no que refere a diversidade de materiais "nada é mais adequado à criança do que irmanar em suas construções os materiais mais heterogêneos", que receberam denotações pedagógicas e foram utilizados para auxiliar no desenvolvimento do conteúdo abordado.

Deste modo, conseguimos ampliar as possibilidades de instrumentalização dos elementos da Cultura Corporal, construindo meios e instrumentos para que tivéssemos uma Educação Física de qualidade. Referimo-nos a 'qualidade' pelo fato de termos saído da situação precária no que diz respeito ao acervo de material pedagógico e termos superado as condições evidenciadas inicialmente. Outro aspecto que merece ser enfatizado foi proporcionar aos educandos reflexões sobre a estrutura escolar, mais especificamente em relação a Educação Física e as necessidades referentes ao ambiente físico e material pedagógico.

Mota; Amaro (2016), Oliveira (2011) e Tahara; Darido; Bahiax (2017) evidenciam a importância das condições adequadas de trabalho para os professores de Educação Física, em especial, referente o espaço físico e a disponibilidade de material, seja em número e/ou em

${ }^{5}$ Foram arrecadados: garrafas pets, tampinhas de garrafa e de detergente, bolinhas de meia, palitos de madeira, pedaços de madeira, rolinhos de papel toalha, fios de lã, sacos, fitas adesivas e papel crepom. 
qualidade, para que, desta forma, propicie uma valorização do componente curricular e um aumento de práticas corporais pelos educandos, proporcionando para o contexto escolar um vasto acervo cultural da Educação Física.

\section{Proposta de Trabalho}

A partir do cenário descrito, de posse dos materiais alternativos, elaboramos nossa proposta de trabalho. Pautamo-nos na concepção de Educação Física denominada Crítico - Superadora, elaborada pelo Coletivo de Autores e divulgada em 1992, cujo objeto de conhecimento da área é a Cultura Corporal, destacando-se como conteúdos o esporte, o jogo, a ginástica, a dança, as lutas, entre outros (BRACHT, 1999). Cultura Corporal, como define o próprio Coletivo de Autores em sua obra Metodologia do Ensino da Educação Física (2012), é:

[...] a materialidade corpórea foi historicamente construída e, portanto, existe uma cultura corporal, resultado de conhecimentos socialmente produzidos e historicamente acumulados pela humanidade que necessitam ser retraçados e transmitidos para os alunos na escola. (SOARES et al., 2012. p.40)

Os conhecimentos acerca da Cultura Corporal necessitam ser transmitidos democraticamente aos alunos na forma de conteúdos, sendo estes uma conquista e produção humana que se transformaram em patrimônio cultural da humanidade estabelecendo como objetivo a possibilidade de proporcionar uma análise crítica do movimento e das manifestações corporais (SOARES et al., 2012). A referida concepção de Educação Física tem suas bases epistemológicas inspiradas, fundamentalmente, na Pedagogia Histórico - Crítica, desenvolvida por Dermeval Saviani no ano de 1984 (SAVIANI, 2013):

As discussões e críticas formuladas a partir do modelo critico-reprodutivista, segundo Saviani, foram consideradas superadas. A teoria critico-reprodutivista, tem a capacidade de realizar a reflexão e a crítica ao existente, podendo explicar os mecanismos, mas não apresenta possibilidades de intervenções práticas sobre analise e/ou fatos da realidade, se limita a constatar e definir que é assim e não pode ser de outro modo. A partir da insatisfação do modelo de análise descrito anteriormente, houve a exigência de um modelo de análise para dar conta do problema educacional, que resultasse em orientações com influxo na prática pedagógica, ocorrendo sua alteração e possibilitando sua articulação com os interesses populares a fim de transformar a sociedade, surgindo a Pedagogia Histórico - Crítica (SAVIANI, 2013. p. 61).

Para planejamento das aulas, adotamos a metodologia dos cinco passos sistematizados por Saviani (2012), seguindo a coerência com a proposta de trabalho e com a concepção de Educação Física que sustentou nossa prática pedagógica. Para melhor contextualizar os procedimentos metodológicos empregados para realização do planejamento das aulas citamos Gasparin (2009) ao 
apresentar e discorrer sobre os cinco passos do processo metodológico que são empregados para materialização da prática pedagógica baseada na relação dialética entre sujeito e conhecimento, ou seja, educando e conteúdo através da mediação do professor:

A Prática Social (inicial) está respaldada no contato inicial do aluno com o conteúdo a ser trabalhado, o aluno apresenta seu conhecimento empírico sobre o tema e conhece o ponto de partida do trabalho. "Frequentemente é uma percepção de senso comum, empírica, um tanto confusa, em que tudo, de certa forma, aparece como natural" (GASPARIN, 2009, p. 16).

A Problematização se refere ao processo de questionamentos e momento de instigar o educando a refletir, analisar, encontrar possibilidades e alternativas para transformar a prática social inicial. Mas, principalmente, refletir criticamente sobre sua realidade, realizando o questionamento do conteúdo escolar com a prática social, considerando os problemas que precisam ser resolvidos no cotidiano pessoal e/ou social. Segundo Gasparin (2009, p.33) "a problematização é um elemento chave na transição entre a prática e a teoria, isto é, entre o fazer cotidiano e a cultura elaborada", bem como, “[...] o momento do processo em que essa prática social é posta em questão, analisada, levando em consideração o conteúdo a ser trabalhado e as exigências sociais de aplicação deste conhecimento" (Idem, p.34).

Por sua vez, a Instrumentalização é a fase de estruturação e desenvolvimento dos conceitos científicos. Momento de transmissão e assimilação dos conteúdos, respondendo as questões evidenciadas na fase anterior. De acordo com o referido autor, o conteúdo é posto a disposição do educando, para que recriem e transformem, sendo o momento em que:

Os educandos e educador agem no sentido da efetiva elaboração interpessoal da aprendizagem, através da apresentação sistemática do conteúdo por parte do professor e por meio da ação intencional dos alunos de se apropriarem desse conhecimento (GASPARIN, 2009.p. 49).

Já a Catarse é o momento de sistematizar o que foi incorporado pelo educando, mostrando que atingiu um nível intelectual mais elevado de conhecimento, assumindo uma nova postura mental. Momento de síntese de entendimento:

[...] a nova postura mental do aluno, que deve ser capaz, neste momento de reunir intelectualmente o cotidiano e o científico, o teórico e o prático, demonstrando, através da avaliação, o quanto se aproximou da solução das questões levantadas e trabalhadas nas fases anteriores do processo pedagógico. (GASPARIN, 2009.p. 9).

Por fim, a Prática Social (final) que ocorre a partir da nova posição do educando em relação ao conteúdo, é o momento de transpor a teoria para uma nova prática, o educando detém uma nova forma de pensar a realidade que constitui a nova prática social final. Assim, apresenta Gasparin 
(2009), “o conhecimento teórico adquirido pelo educando retorna à prática social de onde partiu, visando agir sobre ela com entendimento mais crítico, elaborado e consistente, intervindo em sua transformação" (p. 8).

Ao nos remetermos aos conteúdos, corroboramos com Libâneo (1998, p. 39), ao definir que “os conteúdos são realidades exteriores aos alunos" e, "não basta que os conteúdos sejam apenas ensinados, [...], é preciso que se liguem de forma indissociável a sua significação humana e social”. Dentre os conteúdos da Educação Física optamos em trabalhar com o jogo ${ }^{6}$, que de acordo com Soares et al.(2012), é “ uma invenção do homem, um ato em que sua intencionalidade e curiosidade resultam num processo criativo para modificar, imaginariamente, a realidade e o presente" (p. 65).

No processo do jogar a criança opera suas ações de forma significativa, desenvolvendo sua vontade e ao mesmo tempo tendo as possibilidades de tomadas de decisões e escolhas. Assim o jogo se propõe como elemento para mudar as necessidades e a consciência da criança (SOARES et al.,2012). Isto ocorre devido ao caráter que é atribuído as regras do jogo, podendo ser ocultas, em uma situação de imaginação, e em situações de regras claras e precisas, onde o objetivo está explícito no contexto da atividade.

O trabalho pedagógico foi desenvolvido com uma turma de $4^{\mathrm{a}}$ ano do ensino fundamental e priorizando-se como conteúdo o jogo. Sendo assim, para esclarecermos como o processo de ensinoaprendizagem ocorre nesta etapa devemos considerar a organização pedagógica dos conteúdos a partir dos Ciclos de Escolarização. Estes são fragmentados em quatro fases ${ }^{7}$, em que os conteúdos são tratados simultaneamente e apresentando uma ampliação no pensamento do aluno, ocorrendo de forma espiralada, desde o momento de constatação, interpretação, compreensão e explicação (SOARES et al.,2012).

Encontramo-nos na fase do primeiro ciclo de escolarização, que apresenta as seguintes características, segundo Soares et al. (2012, p. 36),

O primeiro ciclo vai da pré-escola até a $3^{\mathrm{a}}$ série. É o ciclo de organização da identidade dos dados da realidade. Nele o aluno encontra-se no momento da síncrese. Tem uma visão sincrética da realidade. Os dados aparecem (não identificados) de forma difusa, misturados. Cabe à escola, particularmente ao professor, organizar a identificação desses dados constatados e descritos pelo aluno para que ele possa formar sistemas, encontrar as relações entre as coisas, identificando as semelhanças e as diferenças.

\footnotetext{
${ }^{6}$ Os jogos estudados e vivenciados foram: jogo do taco, pique-bandeira, boliche, cabo-de-guerra, jogos indígenas e, ademais, foram construídos brinquedos como: pião e bilboquê.

${ }^{7}$ Os ciclos de escolarização na perspectiva de Soares et al. (2012.p. 36) seguem quatro fases: pré-escola até a $3^{\mathrm{a}}$ série, ciclo de organização da identidade dos dados da realidade; $4^{\mathrm{a}}$ à $6^{\mathrm{a}}$ séries, ciclo de iniciação à sistematização do conhecimento; $7^{\mathrm{a}}$ à $8^{\mathrm{a}}$ séries, ciclo de ampliação da sistematização do conhecimento; $1^{\mathrm{a}}$, $2^{\mathrm{a}}$ e $3^{\mathrm{a}}$ séries do ensino médio, ciclo de aprofundamento da sistematização do conhecimento.
} 
Assim podemos entender o jogo para uma turma de $4^{\circ}$ ano ${ }^{8}\left(3^{a}\right.$ série no modelo antigo de seriação), que este deve oferecer "a possibilidade do conhecimento de si mesmo, do conhecimento dos objetos/materiais de jogos, das relações espaço-temporais e, especialmente, das relações com as outras pessoas" (SOARES et al., 2012, p. 67). O jogo neste ciclo é visto como elemento que propicie as possibilidades de ação implicando na inter-relação do pensamento e das relações sociais, articulado com a convivência coletiva, fazendo uso das regras e dos valores que as envolvem, aplicando a auto-organização e avaliação das atividades e, principalmente, elaboração de brinquedos/material pedagógico, tema da nossa discussão.

$\mathrm{Na}$ sequência nos debruçaremos em discorrer sobre a importância da participação do educando no processo de construção de material pedagógico, trazendo para discussão as contribuições para sua formação educativa e denotar as transformações da realidade escolar/social do educando, propiciada a partir do processo de construção de material pedagógico.

\section{Resultados e discussões}

Nosso propósito está em discorrer sobre o educando enquanto sujeito participativo do processo de construção de material pedagógico, levantando discussões sobre as possíveis contribuições para sua formação educativa, mantendo uma coerência pautada na relação dialética entre os autores apresentados pela proposta de trabalho e/com o processo educativo, ou seja, trazer para discussão o que é destacado pelos autores referente ao educando enquanto sujeito do processo educativo, tendo o professor como mediador deste processo (GASPARIN, 2009).

É importante inferir a necessidade de atenção aos aspectos que envolvem o educando enquanto sujeito do processo de ensino-aprendizagem, como salienta Saviani (2012) situando o educando como agente social. O referido autor menciona que sua teoria deve estar relacionada aos interesses populares, superando os métodos tradicionais e retomando a importância do educando na participação de sua formação educativa,

Serão métodos que estimularão a atividade dos alunos sem abrir mão, porém, da iniciativa do professor; favorecerão o diálogo dos alunos entre si e com o professor, mas sem deixar de valorizar o diálogo com a cultura acumulada historicamente; levarão em conta os interesses dos alunos, os ritmos de aprendizagem e o desenvolvimento psicológico, mas sem perder de vista a sistematização lógica dos conhecimentos, sua ordenação e gradação para efeitos do processo de transmissãoassimilação dos conteúdos cognitivos. (SAVIANI, 2012. p. 69)

${ }^{8}$ lei $\underline{11.274}$; 
Nesse sentido, o autor defende a necessidade e importância da ação participativa do educando nos caminhos educativos, destacando o diálogo entre professor e educando para alcançar um nível mais elevado de conhecimento.

É relevante que tenhamos a compreensão do papel da escola enquanto instituição formal de ensino, propiciando um entendimento da importância dos componentes curriculares tratados na escola e, principalmente, sobre o conteúdo que é abordado pelos mesmos. A escola, como define Saviani (2013, p. 66), “tem o papel de possibilitar o acesso das novas gerações ao mundo do saber sistematizado, do saber metódico, científico. Ela necessita organizar processos, descobrir formas adequadas a essa finalidade". O conteúdo escolar é evidenciado por Gasparin $(2009$, p. 49) como "objeto sistematizado do conhecimento", sendo organizados e apresentados aos educandos com mediação do professor.

Seguindo na mesma linha de raciocínio, apresentamos Soares et al. (2012) ao abordar o conteúdo como conhecimento que:

[...] é tratado metodologicamente de forma a favorecer a compreensão dos princípios da lógica dialética materialista: totalidade, movimento, mudança qualitativa e contradição. É organizado de modo a ser compreendido como provisório, produzido historicamente e de forma espiralada vai ampliando a referência do pensamento do aluno através dos ciclos já referidos. (SOARES et al., 2012, p. 41)

É imprescindível a compreensão da relação dialética entre educando e conteúdo. Se há conteúdos/conhecimentos, estes construídos e transmitidos social, cultural e historicamente pela humanidade em suas relações, torna-se essencial a existência de instrumentos e recursos que auxiliarão nessa transmissão, para que o conhecimento apresente-se de forma facilitada e com clareza ao educando, favorecendo a apropriação do mesmo.

Assim, no trato pedagógico da Educação Física, o material pedagógico torna-se de grande importância, sendo este um recurso facilitador do processo de ensino-aprendizagem do conhecimento que é tratado pelo componente curricular na escola, como defende SOARES et al. (2012, p. 31) no momento em que redige ser "fundamental que criem as condições de sua transmissão e assimilação", ou seja, atribui importância ao material pedagógico dando-lhe condição de instrumento de apoio ao professor na assimilação dos conteúdos.

$\mathrm{Na}$ realidade em que nos encontrávamos - ausência de materiais e/ou instrumentos específicos para auxiliar o professor e educando no processo de ensino-aprendizagem - nos deparamos com duas possibilidades. Primeira, negar ou negligenciar o conhecimento, pelo fato de não termos subsídios materiais para seu acesso; ou segunda, criar e/ou construir possiblidades 
materiais e recursos alternativos para proporcionar aos educandos o contato e a experimentação do novo conhecimento. Optamos, pois, pela segunda opção.

A Educação Física, cuja natureza se caracteriza pela centralidade das vivências de diferentes práticas corporais, necessita de uma gama de recursos materiais e estruturais, pois como ponderam Sebastião; Freire (2009), ao elaborarmos as etapas de planejamento, devemos considerar a especificidade da área como, por exemplo, o uso da quadra e/ou do pátio, de materiais e implementos específicos. No entanto, destacamos que não dependemos única e exclusivamente de materiais pedagógicos para a execução das aulas e que estes recebem funções e características específicas dependendo dos objetivos que permeiam o planejamento e determinam seu uso.

O ápice de nosso trabalho esta ancorado em elencar as contribuições que os educandos obtiveram com a participação no processo de construção dos materiais pedagógicos para seu processo educativo e discorrer sobre a transformação da realidade escolar dos mesmos partindo da participação coletiva.

Como mencionamos anteriormente, ao construir novos recursos materiais, possibilitamos a realização de novas práticas corporais, assim, tendo acesso a outros conhecimentos da Cultura Corporal que eram negligenciados devido à escassez de materiais. Os educandos foram sujeitos de todo o processo de construção dos materiais pedagógicos, sendo estes elaborados pelos e para os educandos.

Dessa forma, tivemos por contribuição uma construção mais elaborada do pensamento a respeito da Cultura Corporal proporcionando um confronto de saberes no momento em que o educando teve acesso ao conhecimento elaborado e sistematizado, podendo compará-lo com o conhecimento popular ou empírico que possuía, como apresenta Soares et al. (2012):

O confronto do saber popular (senso comum) com o conhecimento científico universal selecionado pela escola, o saber escolar, é, do ponto de vista metodológico, fundamental para a reflexão pedagógica. Isso porque instiga o aluno, ao longo de sua escolarização, a ultrapassar o senso comum e construir formas mais elaboradas de pensamento. (SOARES et al., p.33)

Destacamos o novo significado que foi dado ao material que seria descartado, proporcionando ao aluno o entendimento de que podemos reutilizar os objetos, atribuindo novos sentidos a ele, pois para Sebastião; Freire (2009), o manuseio de materiais recicláveis como, por exemplo, copos e garrafas pets, são indispensáveis para proporcionar ao educando uma determinada troca com o meio e estabelecer determinadas atribuições, bem como, novos significados ao brinquedo, ao jogo, enfim, aos novos recursos de ensino. 
Nesta perspectiva, Benjamin (1984) argumenta que a criança faz a história do lixo da história, ou seja, o educando desperta a capacidade de atribuir uma nova vida - novo sentido - ao que seria descartado e, segue o autor, "ninguém é mais sóbrio em relação aos materiais do que a criança: um simples pedacinho de madeira [...] reúne sua solidez no monolitismo de sua matéria, uma exuberância das mais diferentes figuras" (idem, pg. 69). Desta forma o material tornou-se significativo recebendo um valor simbólico, sendo o educando protagonista de sua construção.

Desde a realização do contato inicial com a realidade escolar, que implicava diretamente no trato com conteúdo da Educação Física, até a transformação desta realidade, foram desenvolvidas várias etapas viabilizando as relações necessárias com a metodologia proposta por Saviani (2012) e aqui elucidada por Gasparin (2009). Em um primeiro momento, professor e educando se encontravam na condição de agentes sociais possuindo em comum a situação escolar precária, sendo esta a prática social inicial que proporcionava um caráter de desigualdade em relação às demais etapas de ensino.

Através dos momentos de problematização, foi propiciado ao educando a capacidade de reflexão sobre a realidade escolar, em que o mesmo teve a oportunidade de realizar uma leitura crítica da situação em que se encontrava a partir das condições que estavam postas. Para Saviani (2012, p. 71), estes momentos se constituem em “detectar que questões precisam ser resolvidas", desta forma outra contribuição para formação educativa do educando foi desenvolver a capacidade de analise (crítica) da realidade, não aceitando as condições que estavam/estão impostas pelo sistema, seja ele escolar ou social/politico. Corroborando com este pensamento, Neira; Nunes (2006) destacam que há uma preocupação em fazer com que o educando compreenda a dinâmica das relações sociais nas quais estão inseridos.

A próxima contribuição emergiu pela apropriação dos instrumentos produzidos socialmente e preservados pelos educandos, destacando o passo mais importante do processo de ensinoaprendizagem e se constituindo o momento de construção propriamente dito, em que os educandos realizaram o trabalho de elaborar e materializar os novos instrumentos para as aulas. Elucidamos que o trabalho coletivo e a criatividade foram essenciais, viabilizando as ações e relações entre os educandos favorecendo o número e a diversidade de objetos trazidos para confecção dos novos materiais.

O momento de construção do material pedagógico, a partir da mediação do professor e da relação entre os educandos com os materiais a serem confeccionados, de forma coletiva e criativa, propiciou uma participação ativa dos educandos tanto no processo de construção e criação quanto no processo de utilização dos novos recursos pedagógicos. Oliveira (2015) evidencia o movimento 
de criação do próprio material por parte dos educandos proporcionando-lhes uma interação na participação e execução das atividades, tornando o processo educativo significativo.

Neste sentido, Netto; Pimentel (2008) compreendem que o processo de ensino e aprendizagem dos educandos se materializa de forma concreta, pois, ao executarem a fabricação tanto de locais quanto de materiais, a partir das relações interpessoais, os educandos se envolvem na aprendizagem de forma imediata e objetiva por meio de pesquisas sobre determinado conteúdo, esporte e jogo, passando pelo processo de transformação e elaboração do novo material/instrumento, bem como, passando a interagir com as regras e as técnicas de manuseio dos referidos recursos.

No momento catártico, proporcionamos o entendimento da transformação dos objetos em novos materiais, desta vez assumindo um caráter pedagógico. Gasparin (2009, p. 126) destaca que "na catarse o educando é capaz de situar e entender as questões sociais postas no inicio e trabalhadas nas demais fases", ou seja, produzimos como contribuição a capacidade de entendimento do novo, que elaborado pelo educando, acrescentou outro (novo) significado. Entendemos o novo, a partir da coletividade e da criatividade, segundo a explicação de Kunz; Costa (2015, p. 20), na qual é “[...] estabelecer relações ainda não concebidas, inventar ou descobrir algo novo, ainda não conhecido.”, ou ainda “[...] se referir a um novo significado, um valor diferente a algo já conhecido." Como novo, portanto, caracterizamos os materiais pedagógicos, instrumentos educativos, brinquedos, tudo para uma nova realidade e experiência.

E com a prática social final, podemos relacionar ao momento de igualdade em que chegamos. Depois de todo o processo de construção e de transformação, chegamos ao ponto em que houve equalização (momentânea) entre todas as etapas de ensino, pois todos possuíam os recursos materiais necessários para a realização das aulas de Educação Física e acesso ao conhecimento, dando mais um passo no processo de formação educativa.

Apoiados em Saviani (2012), entendemos o processo educativo como:

[...] passagem da desigualdade à igualdade. Portanto, só é possível considerar o processo educativo em seu conjunto como democrático sob a condição de se distinguir a democracia como possibilidade no ponto de partida e a democracia como realidade no ponto de chegada. (p.78)

Entendemos que os educandos tiveram um avanço progressivo em sua formação educativa, pois passaram de um estágio para outro sendo protagonistas da nova configuração de Educação Física, apoiados em um objetivo, pautado em sair da condição desfavorável e sem recursos para um crescimento intelectual a respeito da Cultura Corporal e transformação de sua realidade. 
A transformação da realidade escolar deu-se pela superação da condição inicialmente encontrada a partir das relações de trabalho entre os educandos e o professor, como apresenta Soares et al. (2012, p. 128) "o homem constrói e transforma o mundo a partir do trabalho", ou seja, o planejamento e a organização do professor juntamente com os educandos através do trabalho coletivo de construção de novos materiais pedagógicos trouxeram a possibilidade de transformação da realidade escolar e edificação de um novo contexto.

Nesta perspectiva, reiteramos que o processo de transformação da realidade escolar, em especial no que se refere às aulas de Educação Física, ocorreu em razão do movimento de reflexãoação, isto é, a partir do conhecimento da realidade escolar e entendimento dos limites postos para o trato com o conhecimento da referida área, houve uma reflexão referente à ação da prática pedagógica a ser elaborada com o intuito de superar os limites estruturais/materiais de forma crítica, coletiva e criativa.

Os educandos, ao apropriarem-se das contribuições que emergiram do processo de construção de materiais pedagógicos, obtiveram um avanço importante para seu processo educativo, indo ao encontro das palavras de Saviani sobre o trabalho educativo, "o ato de produzir, direta e intencionalmente, em cada individuo singular, a humanidade que é produzida histórica e coletivamente pelo conjunto dos homens" (SAVIANI, 2013, p. 13). Produzindo, portanto, formas mais adequadas para atingir o objetivo da superação conjuntural da realidade escolar, possibilitando o acesso ao conhecimento da Educação Física e incorporando em sua corporeidade a produção humana elaborada historicamente.

Deste modo, destacamos o entendimento de Rivera (2008) ao argumentar sobre a elaboração e utilização de materiais pedagógicos não específicos para aulas de Educação Física. O autor pondera que para construção de materiais pedagógicos para auxilio na apropriação dos elementos da cultura humana, deve ser considerada uma série de elementos como, por exemplo, as possibilidades dos educandos, os limites do ambiente e, sobretudo, os objetivos estabelecidos para o desenvolvimento do programa da disciplina.

Ademais, para o autor, o uso dos materiais construídos pelos educandos permite a realização de jogos, esportes e atividades que possam contribuir para o processo de avaliação e concretização dos objetivos educacionais pautados para cada etapa de ensino. Bem como, atender as seguintes finalidades: criticidade diante da lógica mercadológica dos materiais para praticas corporais; conscientização sobre a necessidade de reciclagem e reutilização de materiais; e, algo que consideramos de extrema relevância, ser capaz de criar jogos e construir materiais esportivos a partir do trabalho coletivo e de materiais reciclados, para uso em seu tempo livre em atividades físicas. 


\section{Conclusão}

A realidade evidenciada na escassez de material pedagógico para trabalhar com a disciplina de Educação Física é um dos grandes problemas encontrados pelos docentes que atuam na educação básica no ensino público, junto com problemas de infraestrutura e desmotivação dos alunos, como elucidam alguns estudos já apresentados nesse trabalho.

A situação encontrada favoreceu vislumbrar possibilidades de mudanças oportunizando o trabalho coletivo e a realização da construção de materiais pedagógicos. Esse fato, proporcionou aos educandos o acesso a novos conhecimentos e movimentos da Cultura Corporal e o trato com o conteúdo jogo, transformando a realidade estrutural e material da escola, contribuindo para formação educativa no que se refere a compreensão e modificação da realidade escolar.

A participação do educando no processo de construção de material pedagógico torna-se relevante no que tange a preocupação em constituir um educando sujeito de seu processo educativo, tendo capacidade de leitura de sua realidade e a mobilização coletiva com seus pares e com o professor desencadeando uma ação transformadora na busca de meios para o acesso ao conhecimento e ampliação cultural.

Consideramos que a proposta de trabalho ora desenvolvida com a respectiva fundamentação teórica utilizada, conseguiu transformar a realidade dos educandos, favorecendo possibilidades de transformação e de superação através da análise da realidade escolar, do trabalho coletivo, tomada de decisão em não aceitar o que estava imposto pelo sistema escolar. Bem como, pela construção de uma crítica acintosa numa manifestação coletiva aos aspectos das políticas públicas para educação e, sobretudo, para Educação Física, reivindicando melhores condições de realização do trabalho educativo de forma efetiva e qualificada, e a necessidade de um suporte estrutural/material para a transmissão-assimilação do conhecimento escolar.

A proposta de construção de materiais pedagógicos foi desenvolvida no intuito de apresentar uma possibilidade para a ação docente no trabalho com a disciplina de Educação Física, sendo uma forma de atenuar a adversidade encontrada. Neste sentido, ressaltamos a relevância da abordagem e da transformação da realidade educacional no plano político-pedagógico a partir do referido modo, pois entendemos a pertinência em realizar o uso de materiais pedagógicos vinculados à realidade social da escola e dos educandos, viabilizando também uma compreensão das contradições estabelecidas no interior do processo educativo e das possibilidades de acesso ao conhecimento por parte dos educandos. Ademais, evidenciamos que tanto a equipe diretiva, bem como o professor, devem estar atentos na busca de recursos para a aquisição dos materiais específicos para o trato com 
o conhecimento da Cultura Corporal, possibilitando que o aluno tenha um contato com o material oficial do processo de ensino.

Ousamos afirmar que ao longo desse processo os educandos tiveram a oportunidade de produzir uma consciência crítica sobre a situação nas quais se constroem seu processo educativo, particularmente no que diz respeito à Educação Física e as possiblidades de acesso a uma gama mais ampliada de conhecimentos que integram o referido componente curricular.

Por fim, outro aspecto relevante deste trabalho está em se tratar de uma ação desenvolvida no período de estágio curricular que possibilitou pensar sobre a prática pedagógica enquanto futuro professor, na busca de uma formação de excelência e no compromisso com a natureza da profissão produzir/transmitir conhecimento.

\section{REFERÊNCIAS}

AGUIAR, Camila; ROTELI, Paula; TERRA, Dinah. Construção de Materiais Didáticoscurriculares na Educação Física Escolar. IX EnFEFE - Encontro Fluminense de Educação Física Escolar. A formação de Professores: a licenciatura em foco. Niterói, RJ, 2005. Disponível em: http://cev.org.br/biblioteca/construcao-materiais-didatico-curriculares-educacao-fisica-escolar/

Acesso em: 30 set. 2019.

AMARAL, Cleusa do Nascimento. Subsídios para a Educação Física de $1^{\text {a a }} 4^{\text {a }}$ série. Petrópolis: Vozes, 1988;

BENJAMIN, Walter. Reflexões: a criança, o brinquedo, a educação. Tradução de Marcus Vinicius Mazzari. São Paulo: Summus, 1984;

BETTI, Irene Conceição Rangel. Esporte na Escola: mas é só isso, Professor? Motriz. Vol. 01. № 01, 1999;

BOGDAN, Roberto; BIKLEN, Sari Knopp. Investigação qualitativa em Educação: uma introdução às teorias e aos métodos. Porto. Porto Editora, 1994;

BRACHT, Valter. A constituição das Teorias Pedagógicas da Educação Física. Caderno Cedes. Ano XIX, nº 48, 1999;

FIGUEIREDO, Zenólia el al. Educação Física, ser professor e profissão docente em questão... Pensar a Prática. Vol. 11. № 2, 2008;

GASPARIN, João Luiz. Uma Didática para Pedagogia Histórico-Critica. .5 Ed. Campinas, SP: Autores Associados, 2009.

KUNZ, Elenor; COSTA, Andrize. A imprescindível e vital necessidade da criança: "brincar e Semovimentar". In: KUNZ, Elenor. Brincar e Se-Movimentar: tempos e espaços de vida da criança. - Ijuí: Ed. Unijuí, 2015. 
LIBÂNEO, José Carlos. Democratização da Escola Pública - A pedagogia crítico-social dos conteúdos. São Paulo, Edições Loyola. 1986;

MOTA, Amanda Cristina Silva.; AMARO, Diogo Alves. A realidade vivida pelos professores de Educação Física dentro das escolas. Revista Científica Multidisciplinar Núcleo do

Conhecimento. Ano 1. Vol. 10, 2016.

NEIRA, Marcos Garcia; NUNES, Mario Luiz Ferrari. Pedagogia da Cultura Corporal - crítica e alternativas. Phorte Editora, 2006.

NETTO, Reynaldo Seifert; PIMENTEL, Giuliano Gomes Assis. O ensino do Atletismo nas aulas de Educação Física. Orientação de outra natureza - Secretaria de Estado da Educação do Paraná Núcleo R. de Educação Maringá, Secretaria Estadual de Educação do Estado do Paraná, 2008.

OLIVEIRA, Fabyana. Construção de materiais pedagógicos nas aulas de educação física escolar para o ensino fundamental com o conteúdo atletismo. Trabalho de Conclusão de Curso. Universidade Federal do Rio Grande do Norte, 2015.

OLIVEIRA, Rafael Haide. Problemas e Soluções da Educação Física Escolar: um Estudo Bibliográfico. 2011. 12f. Trabalho de Conclusão de Curso (graduação em Educação Física Licenciatura), Universidade Federal do Rio Grande do Sul, Porto Alegre, 2011.

RIVERA, Daniel. Construccíon de material altyernativo em la Educacíon Física. Revista Digital efdportes. Buenos Aires - Año 13 - $\mathrm{n}^{0} 124$ - setiembro, 2008. Disponível em:

https://www.efdeportes.com/efd124/construccion-de-material-alternativo-en-educacion-fisica.htm. Acesso em: 30 set. 2019.

ROCHA, Maria Silva Pinto de Moura Librandi. Não brinco mais: a (des)construção do brincar no cotidiano educacional. - 2. ed. rev. - Ijuí: Unijuí, 2005;

RODRIGUES, Heitor de Andrade; DARIDO, Suraya Cristina. O livro didático na Educação Física escolar: a visão dos professores. Motriz, Rio Claro, v. 17 n. 1, p. 48-62, jan./mar. 2011.

SACRISTÁN, Gimeno. Los materiales y la enseñanza. In Cuadernos de Pagogia. № 194, p. 10-15, 1991.

SAVIANI, Dermeval. Pedagogia Histórico-Critica: primeiras aproximações. $11^{\mathrm{a}} \mathrm{ed} . \mathrm{rev} .-$ Campinas, SP. Autores Associados, 2013;

SAVIANI, Dermeval. Escola e Democracia. - 42 ed. - Campinas. SP: Autores Associados, 2012;

SEBASTIÃO, Luciane; FREIRE, Elisabete. A utilização de recursos materiais alternativos nas aulas de educação física; um estudo de caso. PENSAR A PRÁTICA 12/3: 1-12, set./dez. 2009.

SOARES, Carmem Lúcia. et al. Metodologia do Ensino da Educação Física. São Paulo: Cortez, 2012; 
TAHARA, Alexander; DARIDO, Suraya; BAHIAX, Cristiano. Materiais didáticos e a educação física escolar. Conexões: Educ. Fís., Esporte e Saúde, Campinas: SP, v. 15, n. 1, p. 368-379, jul./set. 2017.

UFSM. Regimento interno do Centro de Educação Física e Desportos. Santa Maria, maio de 1990. Disponível em: http://w3.ufsm.br/cefd/images/Regimento Interno do CEFD.pdf. Acesso em 17 mar. 2017;

ZABALA, Antoni. A Prática Educativa: como ensinar. Porto alegre: Artmed, 1998;

\section{NOTAS DE AUTOR}

\section{AGRADECIMENTOS}

Não se aplica.

\section{CONTRIBUIÇÃO DE AUTORIA}

Não se aplica.

\section{FINANCIAMENTO}

Não se aplica.

\section{CONSENTIMENTO DE USO DE IMAGEM}

Não se aplica.

\section{APROVAÇÃO DE COMITÊ DE ÉTICA EM PESQUISA}

Não se aplica.

\section{CONFLITO DE INTERESSES}

Não se aplica.

\section{LICENÇA DE USO}

Os autores cedem à Motrivivência - ISSN 2175-8042 os direitos exclusivos de primeira publicação, com o trabalho simultaneamente licenciado sob a Licença Creative Commons Attribution Non-Comercial ShareAlike (CC BY-NC SA) 4.0 International. Esta licença permite que terceiros remixem, adaptem e criem a partir do trabalho publicado, desde que para fins não comerciais, atribuindo o devido crédito de autoria e publicação inicial neste periódico desde que adotem a mesma licença, compartilhar igual. Os autores têm autorização para assumir contratos adicionais separadamente, para distribuição não exclusiva da versão do trabalho publicada neste periódico (ex.: publicar em repositório institucional, em site pessoal, publicar uma tradução, ou como capítulo de livro), com reconhecimento de autoria e publicação inicial neste periódico, desde que para fins não comerciais e compartilhar com a mesma licença.

\section{PUBLISHER}

Universidade Federal de Santa Catarina. Programa de Pós-Graduação em Educação Física. LaboMídia - Laboratório e Observatório da Mídia Esportiva. Publicado no Portal de Periódicos UFSC. As ideias expressadas neste artigo são de responsabilidade de seus autores, não representando, necessariamente, a opinião dos editores ou da universidade. 


\section{EDITORES}

Mauricio Roberto da Silva, Giovani De Lorenzi Pires, Rogério Santos Pereira.

\section{HISTÓRICO}

Recebido em: 18 de Fevereiro de 2019.

Aprovado em: 07 de Novembro de 2019. 